\title{
LED Digital Image Design and Production in Large Stage Performance-Take "Shanghai Science and Technology Festival" Series of Performances for Example
}

\author{
Yuelin Hu \\ Department of Film and Television Arts, Shanghai Publishing and Printing College, Shanghai, China \\ Email: 271038044@qq.com
}

How to cite this paper: Hu, Y. L. (2018). LED Digital Image Design and Production in Large Stage Performance-Take "Shanghai Science and Technology Festival" Series of Performances for Example. Art and Design Review, 6, 148-159.

https://doi.org/10.4236/adr.2018.63015

Received: August 3, 2018

Accepted: August 18, 2018

Published: August 21, 2018

Copyright $\odot 2018$ by author and Scientific Research Publishing Inc. This work is licensed under the Creative Commons Attribution International License (CC BY 4.0).

http://creativecommons.org/licenses/by/4.0/

\begin{abstract}
In recent years, LED digital image design and production in large stage performance is taken more seriously. It not only provides the background atmosphere for the performance, but also becomes part of the stage performance in close combination with the performance. The subject summarizes the work flow of LED digital image design and production in stage performance and introduces the design and production methods of stage LED video through taking series of performances of "Shanghai Science and Technology Festival" for instance. LED digital image design and production in large stage performance is a new study field that integrates video clipping, special effect production and 3D synthesis technology which enrich the stage performance style and improve the visual effect of stage performance.
\end{abstract}

\section{Keywords}

Stage Performance, LED, Digital Image Design and Production

\section{The Application Station of Digital Image Design and Production in Large Stage Performance}

Art needs support from technology, while the progress of technology promotes the development of art. Since the 20th century, the development of digital image has brought tremendous visual revolution to the stage performance. With the development of the cultural industry and the increasing aesthetics of the public, the demand of culture and art increases greatly. Meanwhile, audience put forward higher requirement for stage design than ever before. 
There have been more new styles of performance space with the development of time, such as the experimental stage, the extended stage, the center stage, etc. (Zhang, 2014). The styles and effects of performance are limited to the traditional stage art. Digital image plays a breakthrough role in the creation of stage art and shows new visual space for stage performance so that the application of digital image on contemporary stage art becomes a trend.

At present, digital image is mainly used in stage performance by means of LED, projection, holography and other technologies, such as the first 3D holographic drama Linyu Ruan, multimedia stage drama San Ti in use of projection, and the Spring Festival Gala in 2018.

Among them, LED screen is the most common media of digital image on stage performance.

The use of LED digital image on stage performances could strengthen interaction in order to bring immersive experiences to audience (Li \& Tao, 2016). How to apply digital image effectively to the stage performance has become a major concern for designers.

\section{The Creation Process of LED Digital Image on Large Stage Performance}

\subsection{Demand Analysis of Digital Image Production}

In recent years, LED screen is a major part of the stage in various types of large-scale performances as a whole, and becomes to be more and more important role in the whole activity. The requirements of digital image production are closely related to the quantity and size of LED screens that directly determine the size of digital image frames.

The layout and production of digital images throughout every link of a large-scale performance should fully reflect the overall design requirement of the event. The creation of digital images is based on the finalization of the program flow, which meets the creative requirements from the director and stage art designer by actively communicating and coordinating with the director, the stage art designer and the lighting engineer to fully understand and master the director's intentions in all aspects in order to determine the desired program types of digital video and picture styles.

\subsubsection{Digital Image Resolution Calculation}

Resolution is density and pixels are units, while it is made up of pixels. The appropriate screen resolution is the key to video production ensuring the video on the stage performance not to be deformed and fit perfectly with the LED screen, which reflects the fineness of the screen production. Nowadays, large-scale stage performances are composed of multiple LED screens, which are divided into main screen and sub-screen. The main screen has one piece in general, and the sub-screens have more than one piece. The combination of the main and sub-screens also affects the overall design of the digital image. 
The main LED screen used in the stage on the series of performance in Shanghai Science and Technology Festival is 3.5 meters high and 10.5 meters wide (Figure 1). The ratio of the main picture is 1:3 and the RGB mode is $72 \mathrm{dpi}$. So the resolution is $3072 \times 1024$. The LED sub-screen is 3.5 meters high and 4.5 meters wide. The ratio of the sub-picture on both sides is 4:3 and the RGB mode is $72 \mathrm{dpi}$. So the resolution of sub-screen is $1365 \times 1024$ (Figure 2).

\subsubsection{The Demand for Digital Image Types}

The digital images required for the large-scale stage performance are closely related to the programming. The common digital images on large-scale stage performance mainly include warm-up video, countdown video, theme background, and program video.

The warm-up video is generally used to adjust the atmosphere when the audience enters the venue. The warm-up video of the Shanghai Science and Technology Interpreter Awards Ceremony is the MV of the theme song to match the theme of the event and help the audience to have an overview of the event as they

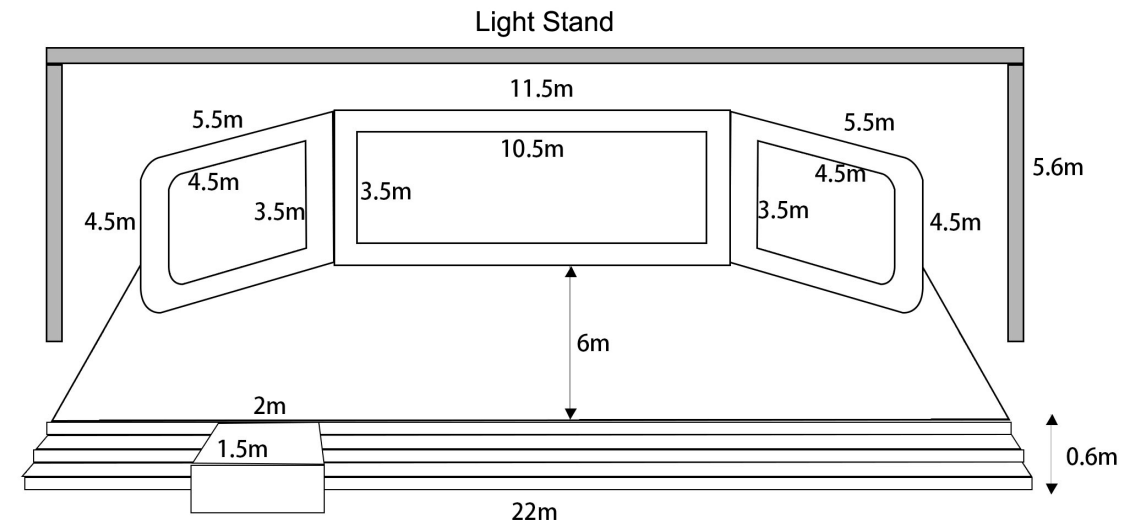

Figure 1. The size of the LED on the performances of Shanghai Science and Technology Festival.

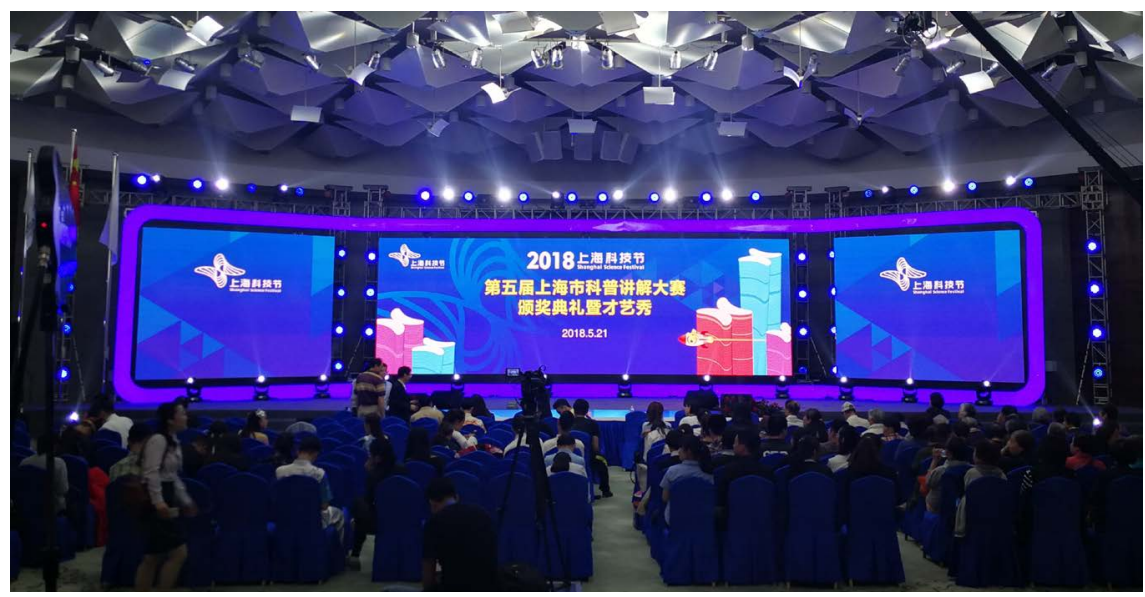

Figure 2. The picture of the stage for the performances of Shanghai Science and Technology Festival. 
enter the venue (Figure 3). The countdown video is generally used to attract the attention of the audience before the performance officially begins and lead the theme by shocking effects in order to pave the way for subsequent programs (Figure 4). The awarding video is used in the awards ceremony, which is composed of the winning information, the award name, the trophy and other elements. Although the awarding video is most important to present the winning information, its visual effect is also important (Figure 5). The image of the theme background is generally used when the host walks up to the stage which must include the important symbols of the theme activity, mascot, theme name and other elements (Figure 6). The program video is presented in conjunction with the performance and need to echo the performance of the actors on the stage (Figure 7).

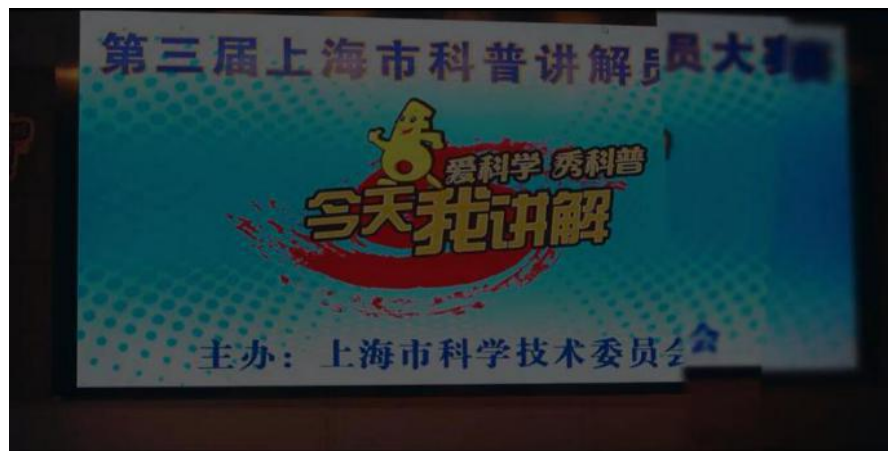

Figure 3. The image of warm-up video.

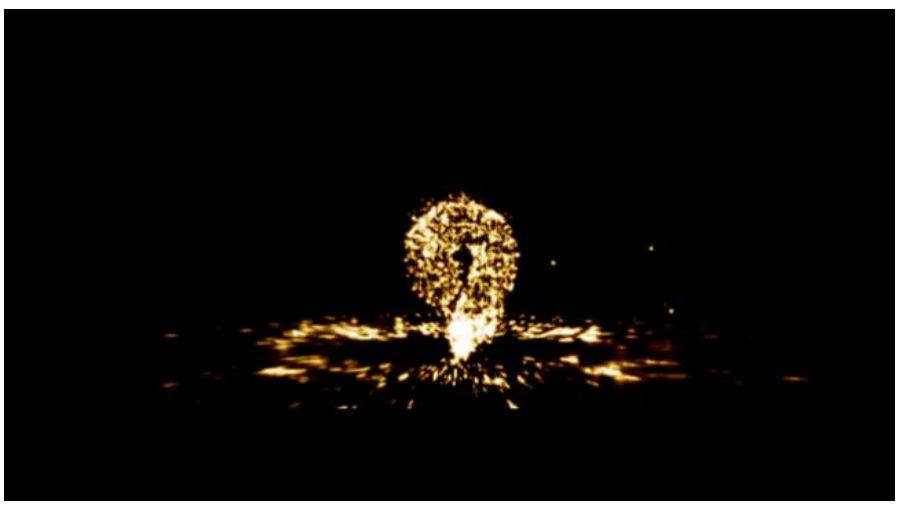

Figure 4. The image of countdown video.

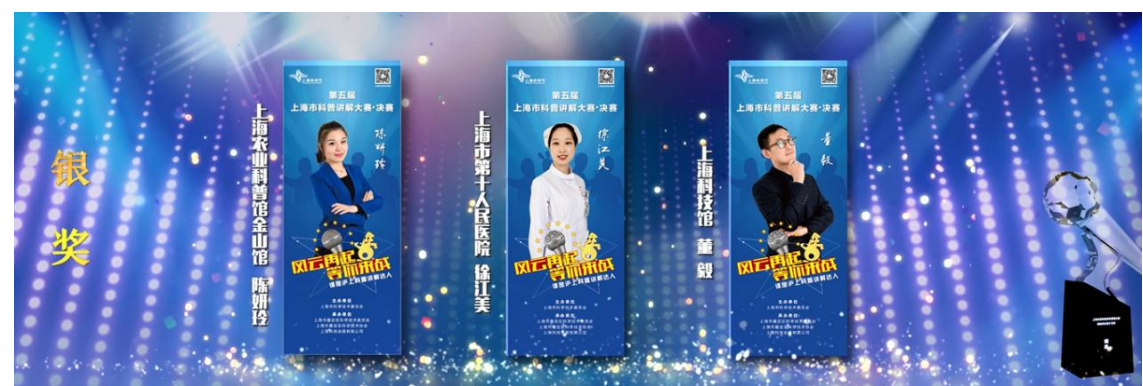

Figure 5. The image of awarding video. 


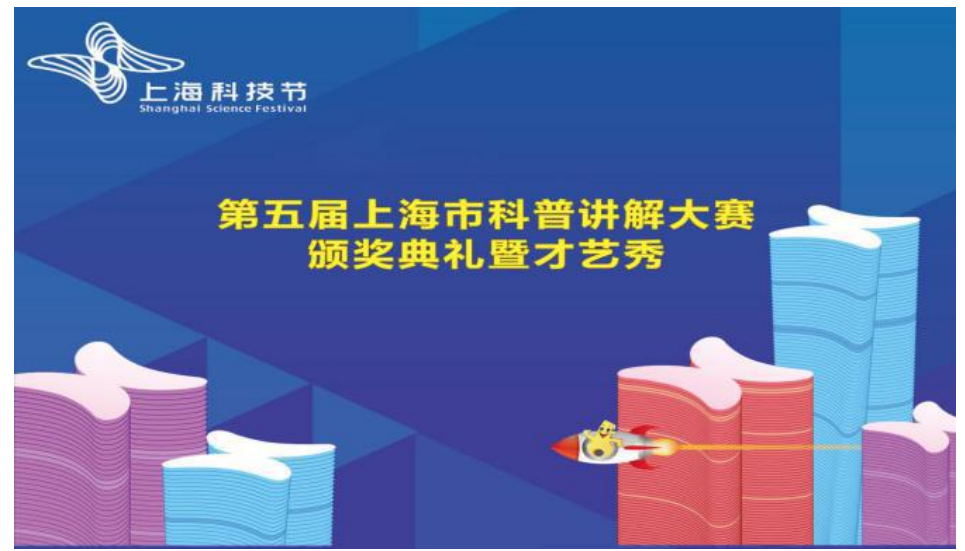

Figure 6. The image of theme background.

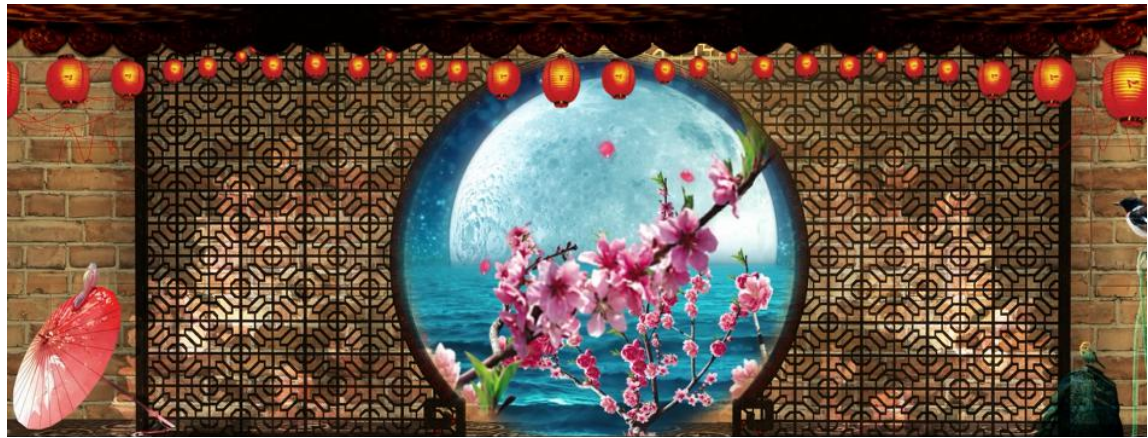

Figure 7. The image of program video.

\subsubsection{The Style Setting of Program Image}

The styles of the programs for the stage performance are very important, which determine the keynote of the styles for program videos. As a result of collective creation, firstly digital images on large-scale performance need a style orientation so that the director's intention, stage designing, lighting, sound and video are unified in one whole. For example, Shanghai Science and Technology Festival Awards Ceremony and Shanghai International Science Show have two different styles of performance.

The overall performance of Shanghai Science and Technology Festival Awards Ceremony highlights the humanistic feelings with strong Chinese traditional style by means of applying more Chinese elements to the digital images of the program while the style of Shanghai International Science Show highlights wisdom, scientific, and dynamics, in the way of cartoon animations to organize all the videos of programs.

\subsection{Digital Image Design and Production}

\subsubsection{Still Frame Design}

Before the video production, we need to design the still frame according to the content and style of the program in order to determine the style of the video on LED screen. The still frame making is the process of a graphic design. Firstly, we confirm the color and composition of it. Secondly, we confirm the design ele- 
ments of the still frame. For example, the performance program named A Moonlit Night on the Spring River consists of four music clips. According to these four music clips, four theme still frames of spring, summer, autumn and winter are designed (Figure 8). For example, spring is composed of moon, boat, river, distant mountains, trees, fishermen and other elements and winter is composed of moon, geese, grass, trees and other elements. These four scenes are all in ink painting style with a strong Chinese style.

\subsubsection{D Effect Graph Making}

$3 \mathrm{D}$ effect graph making for the stage can be used to create a virtual stage that is the same proportion of real stage in the WYS lighting software including lights, props, actors and other items (Figure 9). You can adjust the direction of the light, the angle of view, and so on. Putting the still frame on the LED screen of the virtual stage make the stage effect more realistic.

3D effect graph can help the director, the stage art designer, the lighting designer and other staff to visually understand the stage virtual effect. In otherwise, 3D effect graph help the director to control the visual effect of the entire stage, and also facilitate the communication and coordination among various posts and departments in order to achieve a match to meet them finally.

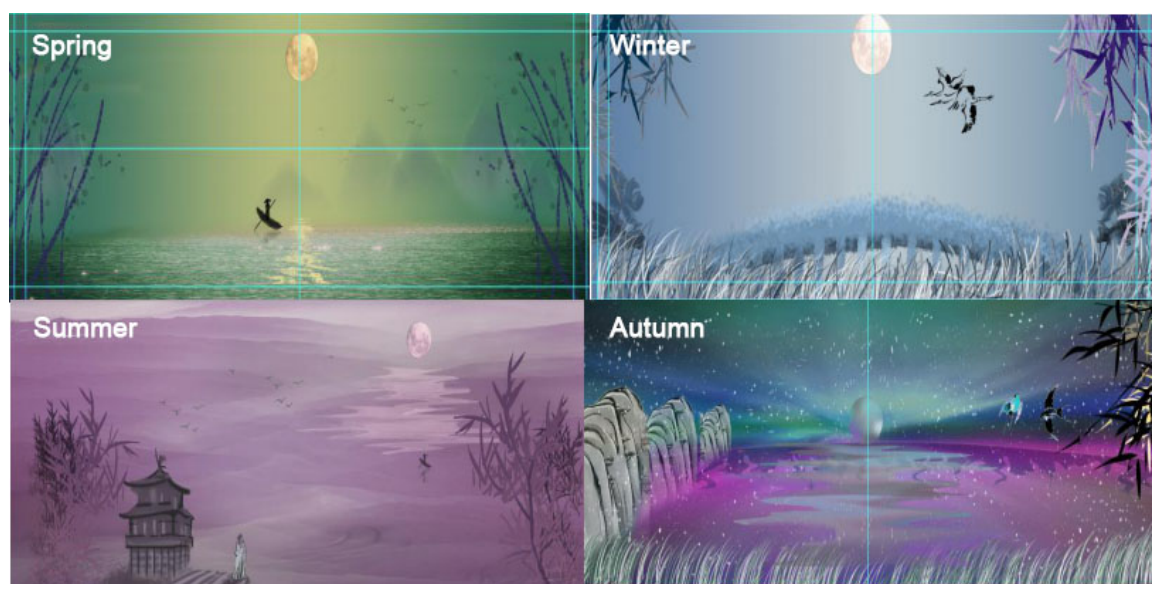

Figure 8. The still frame of A Moonlit Night on the Spring River.

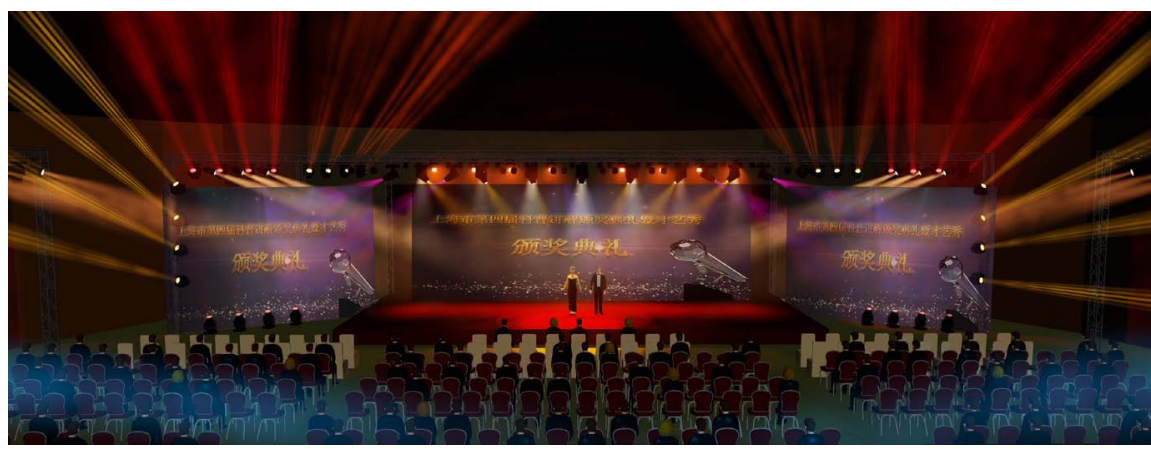

Figure 9. The 3D effect graph of the stage performance of Shanghai Science and Technology Festival. 


\subsubsection{Dynamic Video Production}

The common dynamic effects of digital images for the large-scale stage performance include animation effect, 3D effect synthesis, particle effect, music visualization effect, and laser animation effect.

Animation effects could be realized through using After Effects, a software for video effects making. In the software, key frames could be added to layer properties and effect parameters. For example, there have animation effects on every scene of A Moonlit Night On the Spring River, in which, the river on the Spring scene with the effect of fractal variegation and turbulence by the way of adding key animation frames to the position of the center point of fractal variegated is formed to be flowing. In addition, adding dynamic materials such as snow, leaves, cranes, etc., makes the whole program image to be combined dynamic and static, and have the artistic conception.

There are two situations for applying 3D effect synthesis to the digital image of the stage performance. One of the situation is that the objects related to the performance need to be virtualized in a three-dimensional form in the digital image such as the virtual trophy in the award video of Shanghai Science and Technology Festival (Figure 10). Firstly, the virtual trophy is created in C4D by means of extruding it from various polygon geometries. Secondly, the trophy is add a rotation animation and then is generated sequence animations and depth channel sequence images through multi-channel rendering settings. Finally, synthesis is finished in After Effects by using the depth channel sequence images output as a track mask.

The other one of the situation is that a virtual scene is produced for the program to create an atmosphere. For example, the program Sea Charm used the 3D synthesize technology to make Shi Ku Men in a 3D form that built a virtual scene for the actor to dance and let audience feel return to Shanghai in the 30s of last century which is in line with the cultural characteristics of the performance convey with a sense of time (Figure 11).

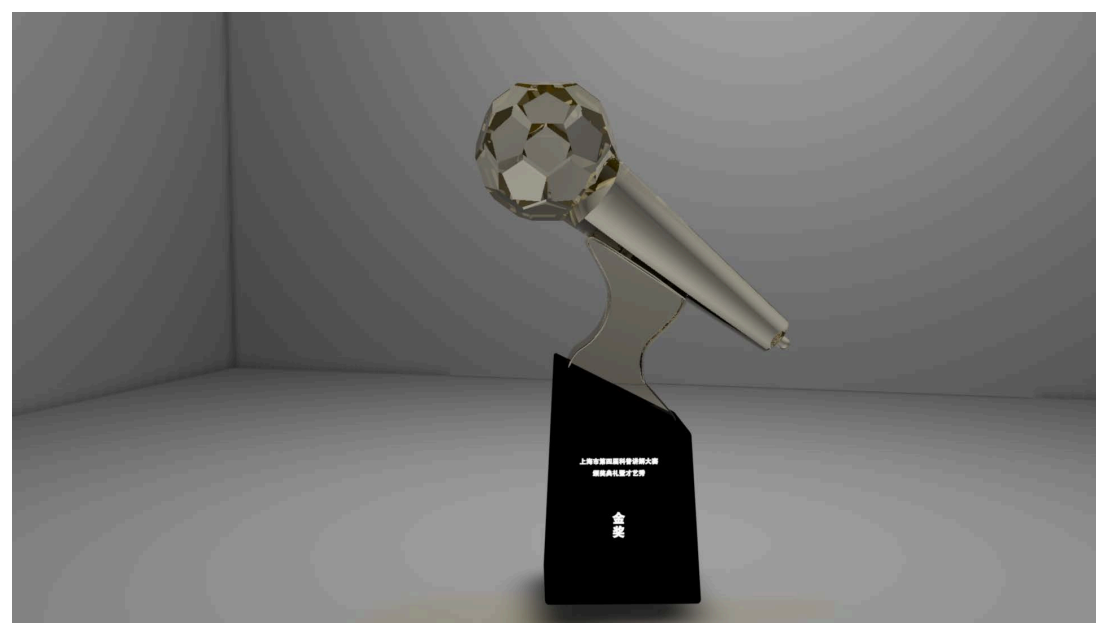

Figure 10. 3D effect synthesis for the award video of Shanghai Science and Technology Festival. 


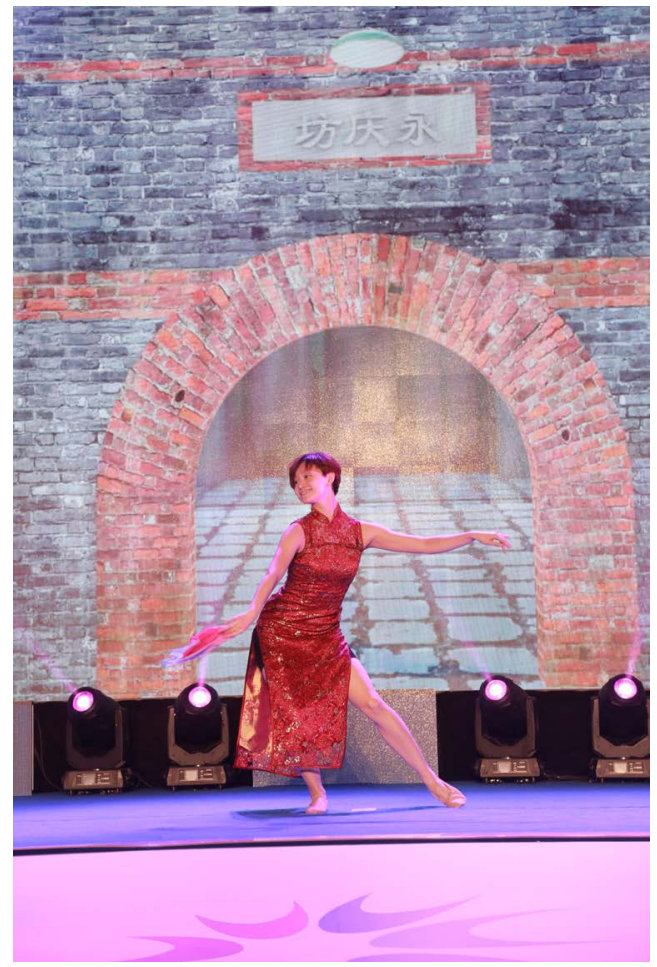

Figure 11. The performance picture of Sea Charm.

Particle effect is widely used in digital images of stage performance, such as fireworks, photo walls, and some transition effects. The program video of The Heart of the Machine on LED screen in Shanghai International Science Show utilizes particle effect to express the abstract concept of the universe, which is pithy and seems to have a third dimension (Figure 12). The process of production is divided into creating geometry objects, effects, and renders based on Plexus effects. Meanwhile, camera animation achieves three-dimensional space shuttle.

Music visualization refers to a mass-based communication method to interpret music by means of images and video which keeps vision as the core, music as the carrier, and the masses as the object of appeal, with the help of a variety of new media technologies and other media (Liu, 2015). The changes of graph are often controlled by the attributes of music such as pitch, volume, timbre, beat, etc., with producing the interactive mapping between auditory and visual elements.

For example, the digital image of Poetic Science in Shanghai International Science Show uses the effect of music visualization (Figure 13). In this video, the colorful geometric figures follow the amplitude or rhythm of the music, which is full of rhythm. Through auditory and visual experience, people have an immersive feeling. In terms of technology implementation, music can be imported into After Effects, and patterns of different shapes are generated with the function of the two expressions of "wiggle ( )" and "time ( )" in order to let patterns' animation follow with the music. 


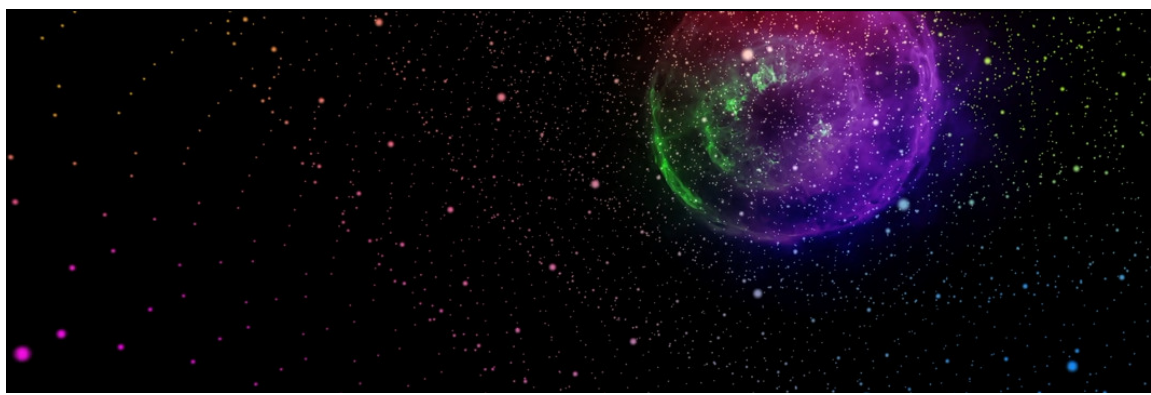

Figure 12. The particle effect of The Heart of the Machine.

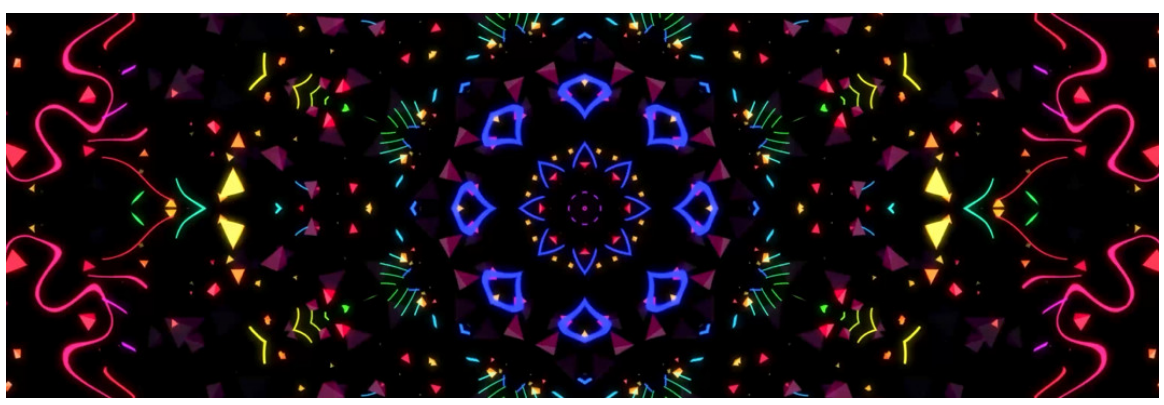

Figure 13. Music visualization.

Based on the performing art, laser light show takes color laser as the carrier with unique creative ideas and incorporates the actors' interactive movements to present dreamy laser images and shadow effects of stunning light from a variety of spaces. The main manifestations of the laser show are laser magic, laser shadow dance, laser drum, cool laser person, laser piano and so on.

The opening laser show of the Shanghai Science and Technology Festival Innovation House Awards Ceremony combines the two stage media elements of laser show and LED video. It tells the story of the family of DuDuLa from music planet, who travel through space to the city and enjoy the interesting of technology and music. The animation of the part of the program's laser show includes the character animation of DuDuLa and the logo of the ceremony. Since the laser animation can only present simple lines, the part of the laser animation make use of the stroke effect to outline the animated character in Flash software and is separately exported according to different color of it to generate a swf format recognized by the laser software. In addition, the elements of the video background such as the universe and technology city are all done in After Effects software (Figure 14). The echo between the characters and the scene, and the blend between the laser and LED video, make the visual effect of the stage sense of more layered, three-dimensional, and shocking.

\section{The Broadcast Control of LED Digital Image on the Stage}

\subsection{The Overview of Video Live Broadcast Control System on Stage}

The most important technical work on performance is how to control the entire 


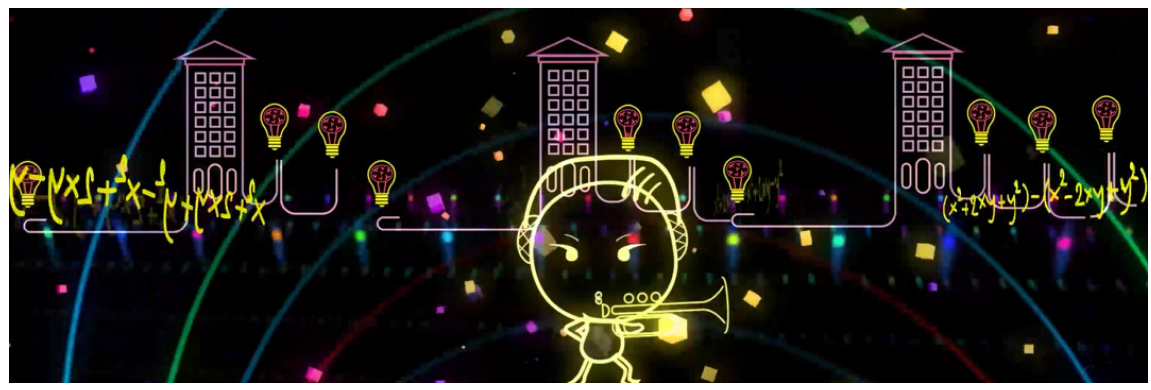

Figure 14. The animation of laser show.

large-screen display system work normally, and to ensure that there can be no mistake during the official performance of the event. Because the slightest loss will affect the success of the entire performance, the system's broadcast control switching system should be very stable and reliable. Before the rehearsal of the stage performance, all the videos on the main and secondary screens are sequentially imported into the relevant software according to the sequence of the program. In addition, the performance always involves the playback of the slides, which requires switching the signal channel as the case may be.

Nowadays, the common live control software for LED background video are PVP and VMIX. Pro Video Player (PVP) is often used in concerts, exhibitions, conferences, etc. The management playlist of Pro Video Player contains the functions of multiple imports of videos, control and editing with the attributes of brightness, saturation, start/stop time, speed, etc. VMIX is a live video production software on PC system with different kinds of parameters. Whether the video playback or live broadcast production, VMIX can handle them. Its "Cut" function can achieve a smooth transition between two videos. Both of the softwares support common video formats such as MOV and MP4.

\subsection{The Fusion Application of Live Broadcast Control on Stage}

\subsubsection{Cooperation with Light}

A wonderful stage performance is the result of the joint cooperation among various types of works. In the beginning of designing the digital image, the video designer should analyze the relationship between the style of the performance and the color of the image in detail, and select the fusion of the colors with a more uniform color or the local comparison of the colors according to the requirements of different scenes in order to achieve the performance effect predicted $(\mathrm{Hu}, 2016)$. For example, the program Spirit of the Birds is kind of a peacock dance, which is the most famous traditional dance in the folk dance of the Dai people in China. The stage lighting designed to create the atmosphere of the tropical rainforest, makes integration with the digital image showing the peacock's opening in the aspect of the color so as to bring an immersive feeling for the audience (Figure 15). In the Kungfu program, the "Fire" theme image on LED screen echoes the dancing red and yellow lights, which help the performance atmosphere go to a climax (Figure 16). 


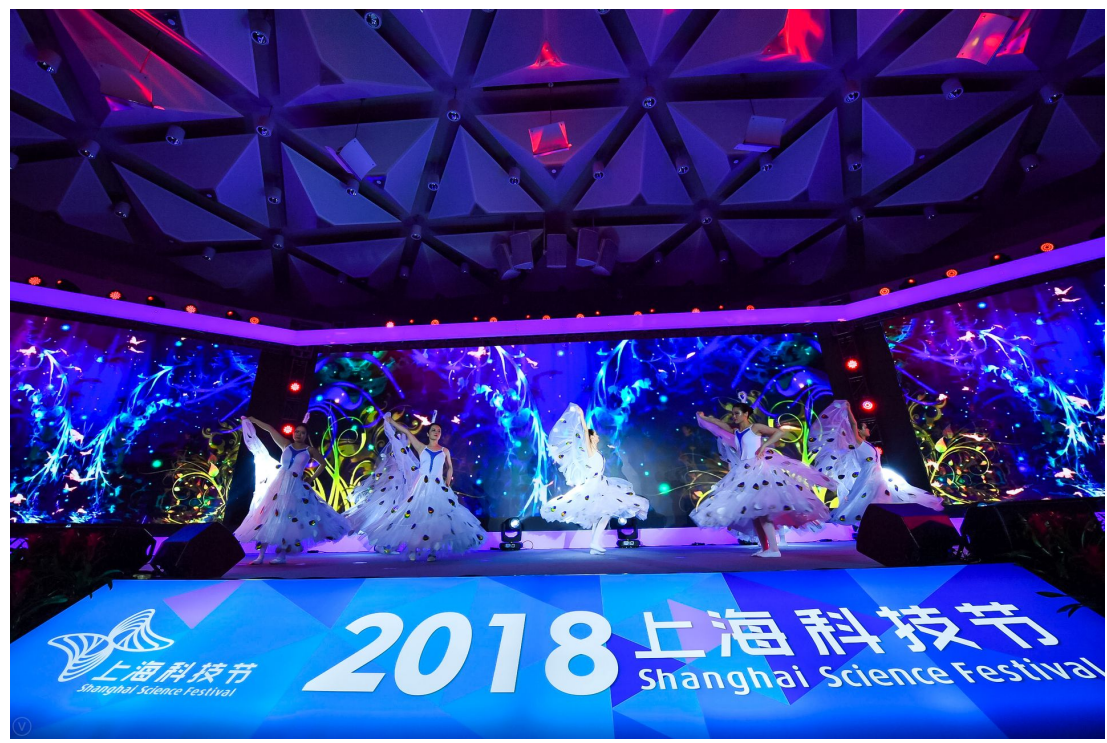

Figure 15. The integration of video and light for Spirit of the Birds.

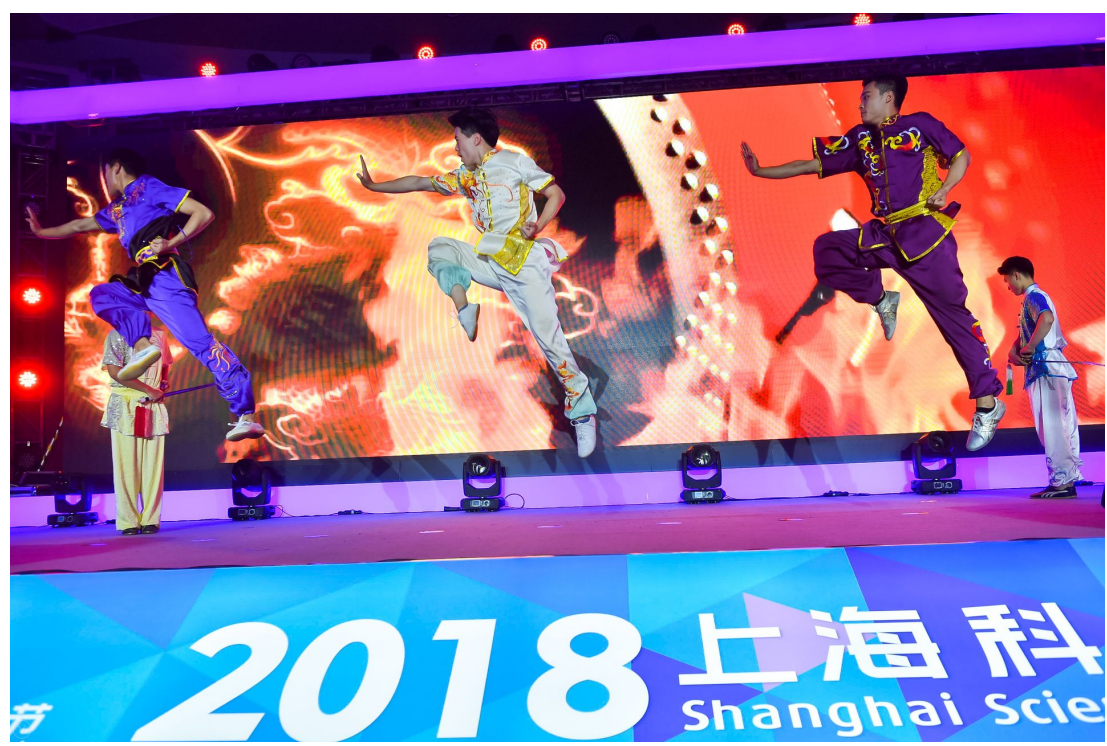

Figure 16. The integration of video and light for the Kungfu program.

\subsubsection{Cooperation with Apparel}

Apparel is also an art and also an important element of the stage performance. The emotions and meanings it can convey are not replaced by the language. The color of the image and apparel should be coordinated. For example, Water Melody is a program of Kunqu opera. The actors wear classical costumes in the color of green and blue. When designing the video background, the digital image on LED screen involves Lou Window, a element of Chinese classical garden, in the form of traditional Chinese ink-wash painting, considering the adoption of Chinese classical style to enhance the expressive power of drama.

\subsubsection{Cooperation with Transition Director}

On the performance of Shanghai Science and Technology Festival, the transition 
director also played a vital role. The work strictly inherits the TV director's profession and norms into the live broadcast. During the performance, the transition director would select the brilliant shots to show on LED screen for the purpose of promoting the charm of art (Zhu, 2010). The virtual effect is the unique effect of TV presentation, as the result of close cooperation between the video designers and transition director.

\section{Conclusion}

With the prosperity and development of the cultural industry, the rapid development of radio and television technology, and the change of computer technology and display technology, the application of the digital image on stage will become more and more extensive. After years of continuous exploration and practice, stage performances have gained rich experience and achievements in the field of the application of the digital image on stage performance.

\section{Conflicts of Interest}

The authors declare no conflicts of interest regarding the publication of this paper.

\section{References}

Hu, M. S. (2016). Stage Design. Shanghai: Shanghai People's Fine Arts Publishing House.

Li, X. X., \& Tao, Z. H. (2016) The Applied Research of Multimedia in Today's Stage Art. Design and Packaging, No. 06, 45-52.

Liu, C. (2015) Exploring the Current Application of Mobile Images in Stage Art Design-By Jared Mezzochi Works as an Example. Modern Decoration (Theory), No. 05, 223-224.

Zhang, Y. (2014). The Application of New Media Technology in Stage Art. Art and Technology, No. 05, 78.

Zhu, C. (2010). Burst and Limitation-Exploration of New Media Images in the Theater Stage. Art and Design (Theory), No. 08, 267-269. 